\title{
Automatic Control of a 30 MWe SEGS VI Parabolic Trough Plant
}

\author{
Thorsten Stuetzle, Nathan Blair, John W. Mitchell, William A. Beckman \\ Solar Energy Laboratory \\ University of Wisconsin-Madison \\ 1500 Engineering Drive \\ USA \\ E-mail: beckman@engr.wisc.edu
}

\begin{abstract}
For the 30 MWe SEGS VI Parabolic Trough Collector Plant, one task of a skilled plant operator is to maintain a specified set point of the collector outlet temperature by adjusting the volume flow rate of the heat transfer fluid circulating through the collectors. For the development of next generation SEGS plants and in order to obtain a control algorithm that approximates an operator's behaviour, a linear model predictive controller is developed for use in a plant model. The plant model is discussed first in this work. The performance of the controller is evaluated for a summer and a winter day. The influence of the control on the gross output of the plant is examined as well.
\end{abstract}

\section{INTRODUCTION}

A solar electric generating system (SEGS), shown in Figure 1, refers to a class of solar energy systems that use parabolic troughs in order to produce electricity from sunlight (Pilkington, 1996). The parabolic troughs are long parallel rows of curved glass mirrors focusing the sun's energy on an absorber pipe located along its focal line. These collectors track the sun by rotating around a north-south axis. The heat transfer fluid (HTF), an oil, is circulated through the pipes. Under normal operation the heated HTF leaves the collectors with a specified collector outlet temperature and is pumped to a central power plant area. There, the HTF is passed through several heat exchangers where its energy is transferred to the power plant's working fluid, which is water or steam. The heated steam is used in turn to drive a turbine generator to produce electricity. The facility discussed in this paper is the 30 MWe SEGS VI plant, constructed in 1988 by Luz International Ltd., and is located in the Mojave desert of southern California.

A skilled operator controls the parabolic trough collector outlet temperature. One of his tasks is to maintain a specified set point for the collector outlet temperature by adjusting the volume flow rate of the HTF within upper and lower bounds. The collector outlet temperature is mainly affected by changes in the sun intensity, by the collector inlet temperature and by the volume flow rate of the HTF. The ambient temperature and the wind speed also influence the outlet temperature but their influence is small. Knowledge of the sun's daily path, observation of clouds and many years of experience and training give the operator the ability to accomplish his task. But there are limitations on the performance of a human controller. Thus, for the development of next generation SEGS plants, it is reasonable to look at automatic controls. In addition, a control algorithm that approximates an operator's behavior can be included in simulation models of SEGS plants.

Automatic control of the HTF in a parabolic trough collector through proportional control has been previously addressed (Schindwolf, 1980). In this study, a linear model predictive controller is developed for the SEGS VI plant. The essential idea behind model predictive control (MPC) is to optimize forecasts of process behavior. The forecasting is accomplished with a process model. Therefore, the model is the essential element of a MPC controller (Rawlings, 2000). The control strategy considers constraints on both the collector outlet temperature and the volume flow rate of the HTF.

The control performance is evaluated through simulations. Consequently it is very important to obtain an accurate model of the plant on which the controller can be tested. The following section deals with the modeling of the plant. The control issue is discussed in a later section. 


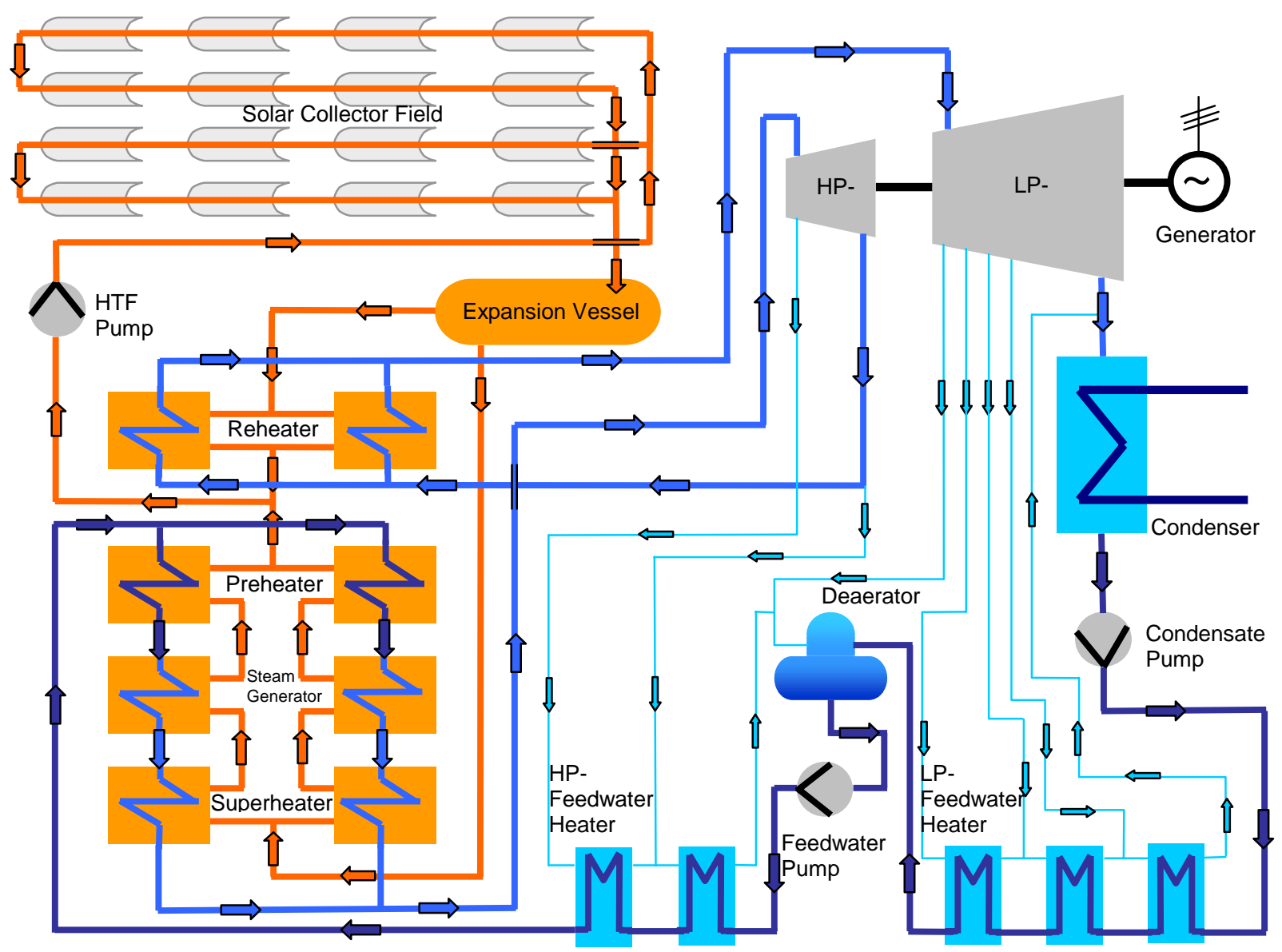

Figure 1 Flow Diagram of the 30 MWe SEGS VI Plant for Pure Solar Mode

\section{THE PLANT MODEL}

In the following the plant is divided into two subsystems: the solar collector field and the power plant. Both are shown schematically in Figure 1.

\subsection{The Solar Collector Field}

The thermal performance model of the SEGS VI parabolic trough plant is based upon a steady-state efficiency model for the collector using empirical coefficients (Lippke, 1995). These coefficients were obtained experimentally on a test facility at SANDIA.

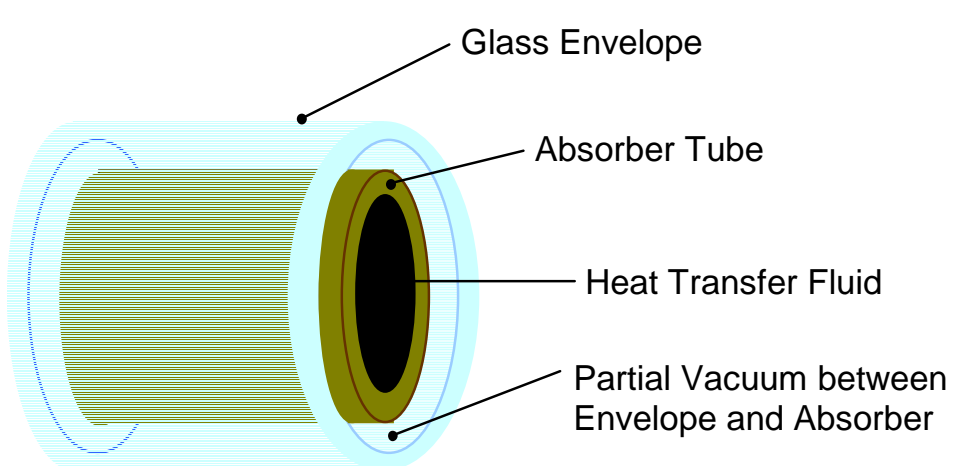

Figure 2 The Heat Collection Element 
A detailed physical model for the collector is presented in this work. To derive the appropriate differential equations, the heat collection element (HCE) in Figure 2 is considered. The HCE consists of the absorber pipe in which the HTF flows. A glass envelope covers the absorber pipe, which is assumed to have no radial temperature gradients. Partial vacuum exists in the annulus between the absorber pipe and the glass envelope. A Transient energy balance for the HTF leads to the following partial differential equation for the HTF temperature:

$$
\rho_{H T F} c_{H T F} A_{A B S, i} \frac{\partial T_{H T F}}{\partial t}=-\rho_{H T F} c_{H T F} \dot{V}_{H T F}(t) \frac{\partial T_{H T F}}{\partial z}+\pi D_{A B S, i} h_{A B S, H T F}\left(T_{A B S}-T_{H T F}\right)
$$

with $\rho_{H T F}, c_{H T F}, T_{H T F}$ as the HTF density, specific heat and temperature. The cross-sectional area of the inside tube of the absorber is $A_{A B S, i}$ and the inside diameter of the absorber tube is $D_{A B S, i}$. The heat transfer coefficient determining the heat transmitted between the absorber and the HTF is $h_{A B S, H T F}$. The HTF volume flow rate is $\dot{V}_{H T F}$. Note that the delay time varies from approximately 3 minutes at the minimum flow rate to 0.5 hour at the maximum flow rate. The distance along the collector is $z$, and $t$ is the time. The boundary condition for equation (1) is

$$
T_{H T F}(0, t)=T_{H T F, \text { inlet }}(t)
$$

with $T_{H T F, \text { inlet }}$ as the HTF collector field inlet temperature. The initial condition for equation (1) is

$$
T_{H T F}(z, 0)=T_{H T F, 0} \cdot
$$

The differential equation for the absorber temperature is given through

$$
\rho_{A B S} c_{A B S} A_{A B S} \frac{\partial T_{A B S}}{\partial t}=Q_{\text {absorbed }}-Q_{\text {internal }}-\pi D_{A B S, i} h_{A B S, H T F}\left(T_{A B S}-T_{H T F}\right)
$$

with $\rho_{A B S}, c_{A B S}, T_{A B S}$ as the absorber density, specific heat and temperature. The cross-sectional area of the absorber is $A_{A B S}$. The absorbed solar energy is $Q_{\text {absorbed }}$ and $Q_{\text {internal }}$ is the heat transfer between the absorber and the envelope. The initial condition for equation (4) is

$$
T_{A B S}(z, 0)=T_{A B S, 0}
$$

The glass envelope is assumed to have no radial temperature gradients. The differential equation for the envelope temperature is given through

$$
\rho_{E N V} c_{E N V} A_{E N V} \frac{\partial T_{E N V}}{\partial t}=Q_{\text {internal }}-Q_{\text {external }}
$$

with $\rho_{E N V}, c_{E N V}, T_{E N V}$ as the envelope density, specific heat and temperature. The heat transfer between the envelope and the environment is $Q_{\text {external }}$. The initial condition for equation (6) is

$$
T_{E N V}(z, 0)=T_{E N V, 0}
$$

The heat transfer coefficient, $h_{A B S, H T F}$, is calculated through the Dittus-Boelter equation for turbulent flow in circular tubes. The heat transmitted between the absorber and the envelope, $Q_{\text {internal }}$, is calculated from free convection flow in the annular space between long, horizontal, concentric cylinders and radiation. The heat transfer between the envelope and the environment, $Q_{\text {external }}$, is estimated through relations for a circular cylinder in cross flow and radiation.

The absorbed solar energy, $Q_{\text {absorbed }}$, is the direct normal solar radiation that is absorbed by the absorber after accounting for optical losses. Because of the north-south tracking of the collectors, only the direct normal solar radiation times the cosine of the angle of incidence is available as heat energy (Duffie \& Beckman, 1991). This 
energy is further reduced through mirror reflectivity, dirt on the mirrors, transmissivity of the envelope, absorptivity of the absorber, the mutual shading of the collectors during the sun rise and the sun set, end losses and additional losses due to shading by the HCE arms and bellows. The parameters to calculate these losses were taken from an experimentally verified steady-state model developed at SANDIA (Mancini, et al. 2001).

The solar collector field model predicts the solar collector field outlet temperature well, especially for days with good weather conditions. Figure 3 shows the predicted and measured solar collector field outlet temperature for December 14, 1998, which was a cloudy day. Even for a day with bad weather conditions, the predicted temperature matches the measurement sufficiently.

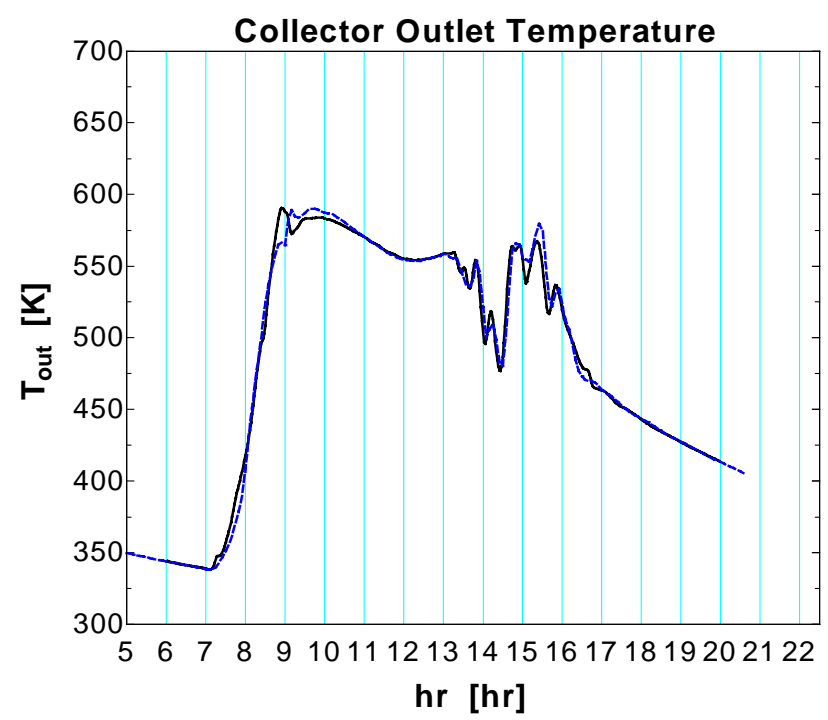

Figure 3 Collector Outlet Temperature of the Solar Collector Field for December 14, 1998. The solid line represents the Outlet Temperature calculated through the Solar Collector Field Model whereas the dashed line represents measured Data.

\subsection{The Power Plant}

The power plant, as seen in Figure 1, is a Rankine cycle with reheat and feedwater heating. For simplicity, each heat exchanger network, consisting of preheater (economizer), steam generator (boiler) and superheater is treated as a single heat exchanger in the model. In the same manner, the two high-pressure feedwater heaters are modeled as one high-pressure feedwater heater and the three low-pressure feedwater heaters are modeled as one single low-pressure feedwater heater. The power plant model is a steady-state model. The effectiveness and the heat transfer coefficients in the heat exchangers are functions of the steam / water mass flow rate. The pump and turbine efficiencies are assumed to be constant, with values taken from (Lippke, 1995).

\section{LINEAR MODEL PREDICTIVE CONTROL}

For the following discussion of the linear model predictive control concept, it is useful to think of the plant model as a block with inputs and outputs as it is shown in Figure 4.

The plant model inputs not used for control are the cooling water inlet temperature at the condenser, the steam or water mass flow rate in the power plant, $\dot{m}_{\text {Steam }}$, and environmental data as the solar radiation, $S$, the ambient temperature, $T_{a m b}$, and the wind speed, $v_{\text {Wind }}$. The input that is used to control the collector outlet temperature, $T_{\text {out }}$, is the HTF volume flow rate, $\dot{V}_{H T F}$. The MPC controller measures the collector outlet temperature and calculates the HTF volume flow rate, which is then injected into the plant model. The environmental data, the steam mass flow rate and the heat exchanger water inlet temperature, $T_{\text {Water }}$, are treated as measured disturbances and are known by the controller as well. 


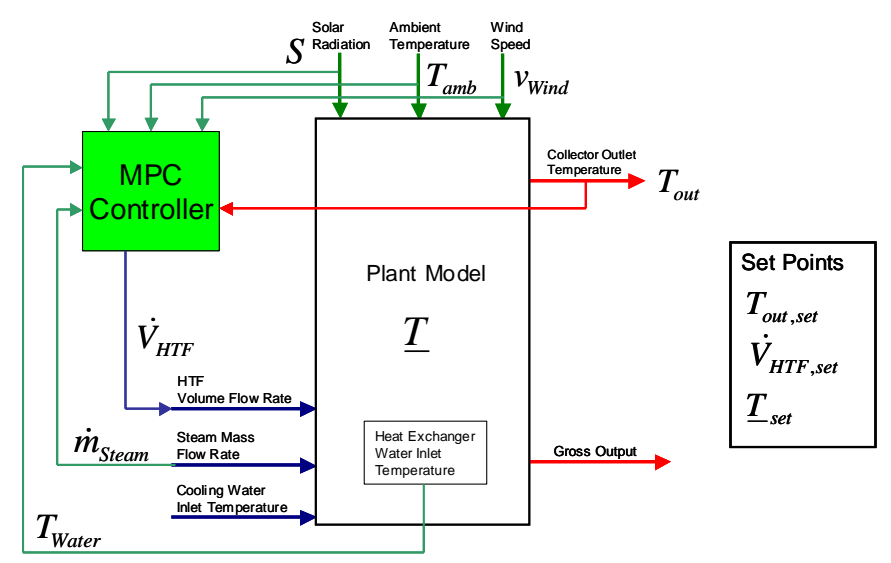

Figure 4 Block Diagram with Plant Model and Controller

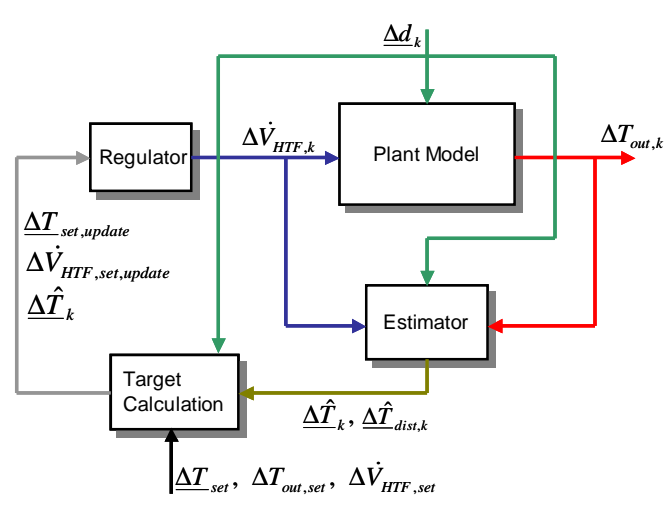

Figure 5 MPC Controller

States of the collector model, $\underline{T}$, are given through the differential equations (1), (4) and (6). Discretization in the $z$ direction transforms the partial differential equations into a set of nonlinear ordinary differential equations

$$
\frac{d \underline{T}}{d t}=\underline{H}\left(\dot{V}_{H T F}, \underline{T}\right)+\underline{q}\left(S, T_{a m b}, v_{\text {Wind }}\right)
$$

with initial conditions

$$
\underline{T}(0)=\underline{T}_{0}
$$

The outlet temperature measurement is given by

$$
T_{\text {out }}=\underline{h}(\underline{T}) .
$$

The set of ODEs given by equation (8) is linearized and transformed into a time discrete form

$$
\underline{\Delta T}_{k+1}=\underline{\underline{A \Delta T}} \underline{\underline{B}}+\underline{B} \Delta \dot{V}_{H T F, k}+\underline{\underline{G_{d}}} \underline{\underline{\Delta d}} k
$$

at time $k$. An additional linear differential equation for the collector inlet temperature with respect to the collector outlet temperature, the steam mass flow rate and the heat exchanger water inlet temperature was added to equation (11). Hence the disturbance vector, $\underline{\Delta d} k$, is of the form

$$
\underline{\Delta d}_{k}=\left[\begin{array}{c}
\Delta S_{k} \\
\Delta T_{\text {amb }, k} \\
\Delta v_{\text {Wind }, k} \\
\Delta \dot{m}_{\text {Steam }} \\
\Delta T_{\text {Water }, k}
\end{array}\right] .
$$

The initial condition for equation (11) is $\underline{\Delta T}_{0}$ and the measurement is

$$
\Delta T_{\text {out }, k}=\underline{C} \underline{\Delta T_{k}}
$$


Set points for the plant model are defined for the collector outlet temperature, $T_{\text {out }, \text { set }}$, for the HTF volume flow rate as the input, $\dot{V}_{H T F, \text { set }}$, and for the states, $\underline{T}_{\text {set }}$. For the linearized model, these set points become $\Delta T_{\text {out } \text {,set }}$, $\Delta \dot{V}_{H T F, s e t}$ and $\underline{\Delta T}_{s e t}$.

A structure of a MPC controller is shown in Figure 5 (Rawlings, 2000). It consists of the receding horizon regulator, the state estimator and the target calculation.

\subsection{Receding Horizon Regulator}

The receding horizon regulator is based on the minimization of the following objective function at time $k$ (Rawlings, 1993).

$$
\min _{\underline{\Delta} \dot{V}_{H T F}^{N}} \sum_{j=0}^{\infty}\left(Q\left(\Delta T_{\text {out }, k+j}-\Delta T_{\text {out }, \text { set }}\right)^{2}+S \Delta \Delta \dot{V}_{H T F, k+j}^{2}\right)
$$

where $Q$ is a penalty parameter on the difference between the actual collector outlet temperature and the set point temperature. The parameter $S$ is a penalty parameter on the rate of change of the HTF volume flow rate as the input in which $\Delta \Delta \dot{V}_{H T F, k+j}=\Delta \dot{V}_{H T F, k+j}-\Delta \dot{V}_{H T F, k+j-1}$. Penalizing the rate of change of the input can be useful for a better attenuation of possible oscillations, which might occur in the controlled collector outlet temperature. The vector $\underline{\Delta}_{H T F}^{N}$ contains $N$ future optimal open-loop control moves where the first input value in $\underline{V}_{H T F}^{N}$, $\Delta \dot{V}_{H T F, k}$, is injected into the power plant model. In addition, constraints on the collector outlet temperature, on the HTF volume flow rate and on the rate of change of the HTF volume flow rate can be considered.

\subsection{State Estimator}

The state estimator is a linear observer that estimates the states of the system from the input (the HTF volume flow rate), the measured disturbances (environmental data, steam mass flow rate, heat exchanger water inlet temperature), and the measurement of the collector outlet temperature. Ideally the linear model should predict the same states as the actual process (in this case the non-linear detailed plant model). The differences between the collector outlet temperatures as predicted by the linear model and the detailed model are multiplied by an observer gain and fed back to the linear model to minimize the difference. The observer gain is calculated as the discrete steady-state Kalman filter gain with the intention to minimize the mean-square error of the state estimate.

The regulator with the estimator described above would not be able to control the collector outlet temperature to the set point without exhibiting an offset. That's why integral action in the controller is very often desirable. As part of the integral action implementation, it is assumed, that the difference between the collector outlet temperature prediction of the estimator and the measurement is caused by an input step disturbance, which in turn is estimated as well. In some cases, integral action in the control can decrease stability due to increasing differences in the dynamic between the linear model used in the controller and the nonlinear plant model on which the controller acts.

\subsection{Target Calculation}

For offset-free control, the set point used in the receding horizon regulator has to be updated with respect to the measured disturbance and the estimated difference between the collector outlet temperature prediction and the measurement. The latter represents the second part of the integral action implementation. The target calculation is formulated as a mathematical program to determine the new set point. 

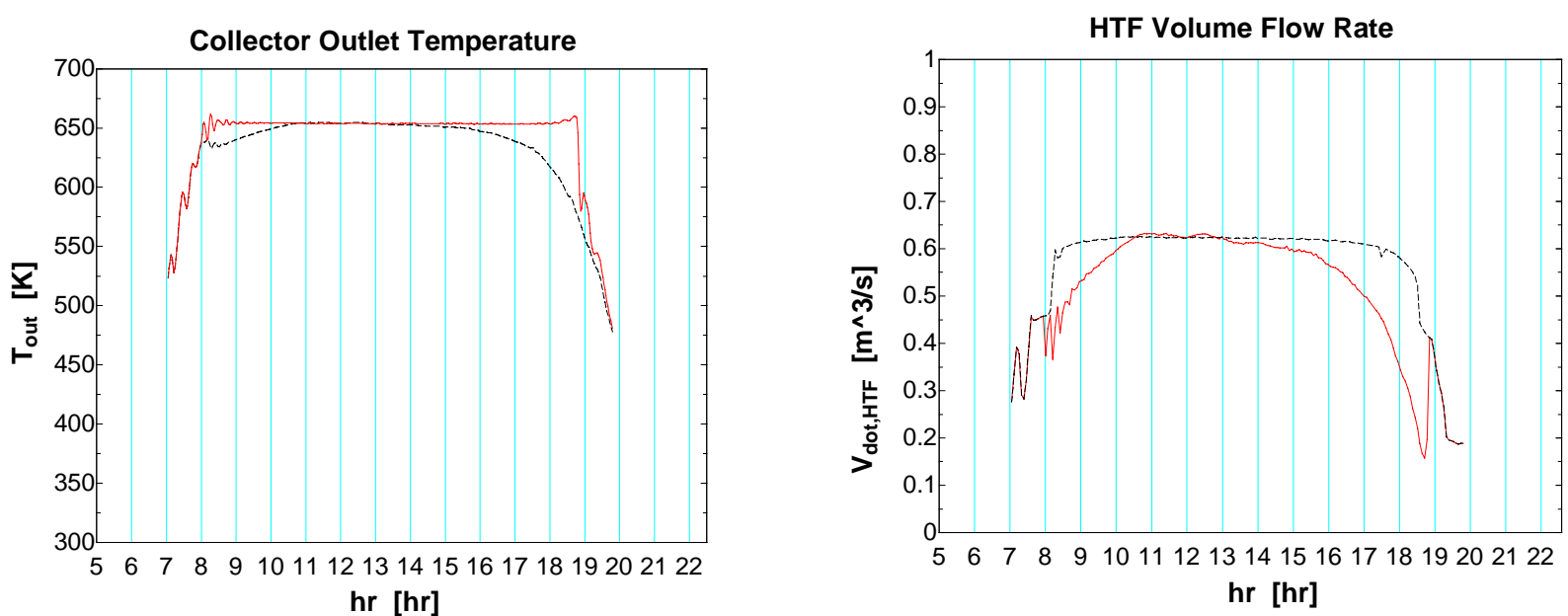

Figure 6 Collector Outlet Temperature and HTF Volume Flow Rate for June 20, 1998. The Collector Outlet Temperature is simulated. For the HTF Volume Flow Rate, the dashed line represents the measured input for a human controller on that day and the solid line represents the input generated through automatic control.
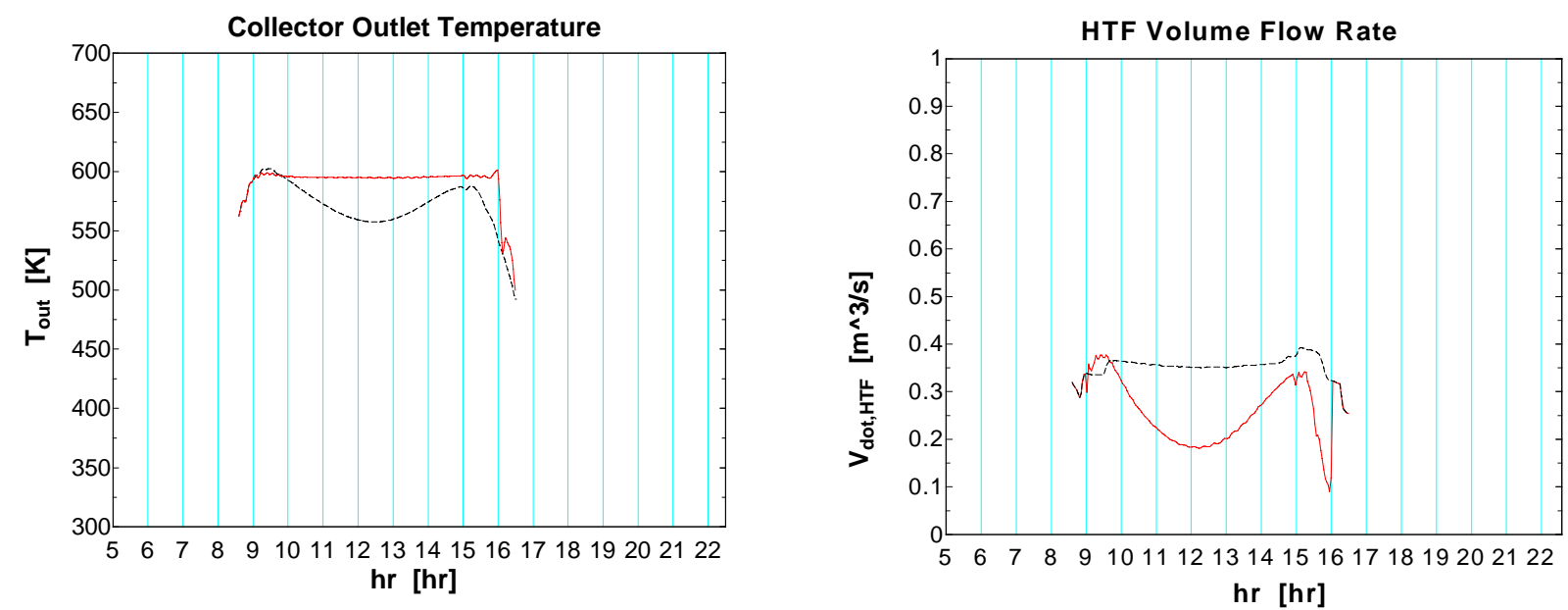

Figure 7 Collector Outlet Temperature and HTF Volume Flow Rate for December 16, 1998. The Collector Outlet Temperature is simulated. For the HTF Volume Flow Rate, the dashed line represents the measured input for a human controller on that day and the solid line represents the input generated through automatic control.
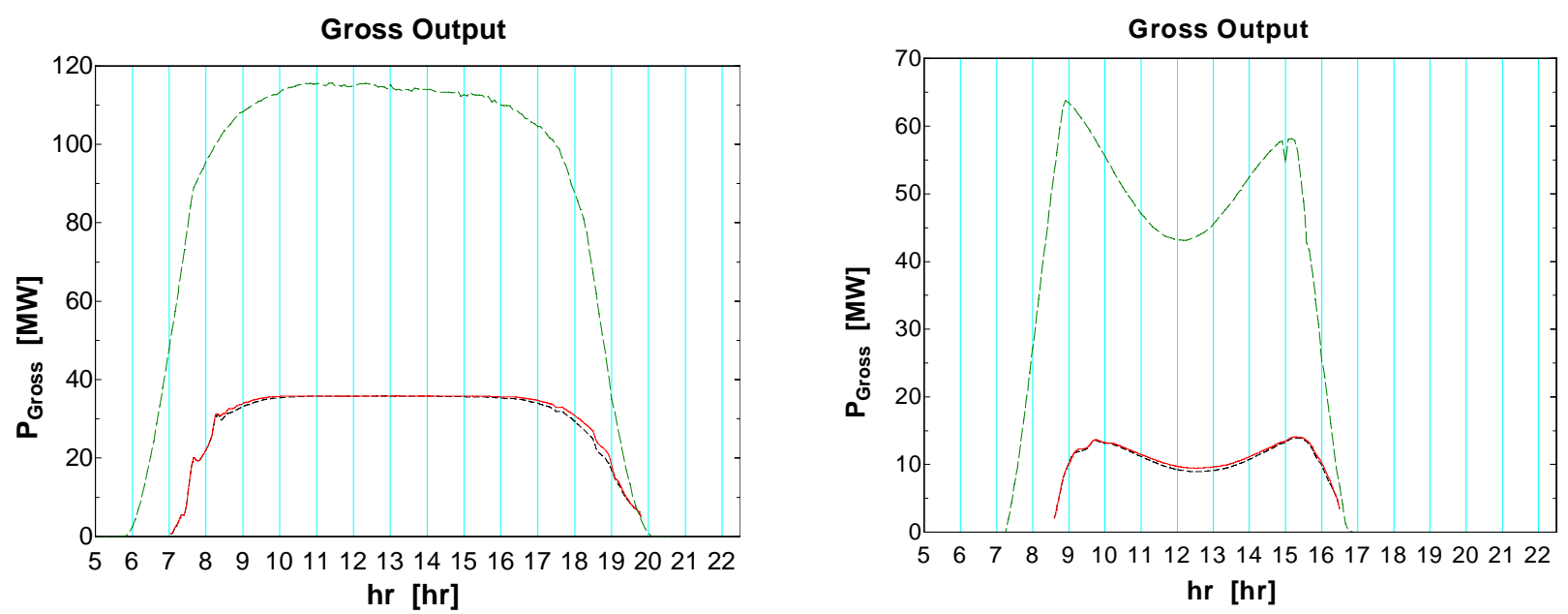

Figure 8 Gross Output, calculated through the Power Plant Model. The left figure shows the Gross Output for June 20, 1998 and the right figure shows the Gross Output for December 16, 1998. The smalldashed line represents the Gross Output with human control. The solid line represents the Gross Output with automatic control. The long-dashed line shows the useful energy (see text) 


\subsection{Results}

The performance of the controller is shown in Figures 6, 7 and 8. Two different days are considered. Figure 6 shows the collector outlet temperature and the HTF volume flow rate for June 20, 1998. For the HTF volume flow rate, the dashed line represents the adjustment made by a human controller on that day. The related collector outlet temperature, calculated through simulation with the discussed plant model, is the dashed line in the left figure. The HTF volume flow rate shown as solid line represents the input calculated through model predictive control. The solid line in the left figure is the corresponding collector outlet temperature. The automatic controller is turned on at $8.00 \mathrm{hr}$ in the morning and turned off at $18.8 \mathrm{hr}$. The start up and shut down is assumed to be done by a human. The automatic controller obtains the ability to hold the collector outlet temperature at a constant set point $(653.9 \mathrm{~K})$ for a long time throughout the day. Its performance is better than the performance of the human controller. The occurrence of oscillations when starting the automatic control and before this controller is turned off are due to increasing differences between the linear model used in the controller and the nonlinear model as the controlled plant when reaching the transient.

In Figure 7, the collector outlet temperature and the HTF volume flow rate are shown for December 16, 1998. Again, dashed lines represent human control and solid lines represent automatic control. During winter days, when the energy in the system is relatively low, the model behavior tends to become more nonlinear. That's why integral action is excluded on that day in the automatic controller. The linear model used to control on a winter day is different from the linear model used for the control on a summer day. The automatic controller is turned on at 9:00 hr and turned off at 16:00 hr. Although a small offset between the automatically controlled collector outlet temperature and the set point $(597.3 \mathrm{~K})$ can be seen, the automatic control action results in a collector outlet temperature much closer to the set point compared to the human controlled one.

The left hand figure in Figure 8 shows the calculated gross output for June 20, 1998. The small-dashed line represents the gross output for human control. The solid line represents the gross output for automatic control. As can be seen from the two plots, the fact that the automatic controller shows a better performance than the human controller in generating a constant set point collector outlet temperature, does not improve the gross output remarkably. As an illustration of efficiency, the useful energy is plotted in the graph as well.

The right hand figure in Figure 8 shows the calculated gross output for December 16, 1998. Also in this case, there is no remarkable improvement in the gross output through automatic control.

\section{CONCLUSIONS}

A nonlinear model of the 30 MWe SEGS VI parabolic trough plant has been established. The model consists of a dynamic model for the collector field and a steady-state model for the power plant. It was used to examine the linear model predictive control strategy for maintaining a specified constant collector outlet temperature on a summer day and a winter day when the power plant was operating in pure solar mode. The implemented MPC controller showed the capability to hold the collector outlet temperature close around the specified set point for a long time during a day. The automatic controller demonstrated a better control of the collector outlet temperature than the human control. However, the improvement in the predicted gross output of the power plant due to the better control of the collector outlet temperature is small.

Further studies should include the model predictive control strategy with the objective to maximize the gross output. Controlling both, the HTF volume flow rate and the steam mass flow rate in the power plant could help improving the daily gross output of the parabolic trough plant.

\section{ACKNOWLEDGEMENTS}

Sandia National Laboratories is a multi-program laboratory operated by Sandia Corporation, a Lockheed Martin Company, for the United States Department of Energy under Contract DE-AC04-94AL85000. The assistance of Scott Jones of Sandia National Laboratory is greatly appreciated. 


\section{REFERENCES}

Duffie, J.A and Beckman, W.A. (1991), Solar Engineering of Thermal Process, John Wiley \& Sons, Inc., New York.

Rawlings, J.B. and Muske, K.R. (1993), Model Predictive Control with Linear Models, AIChE Journal, 39 (2), 262-287.

Rawlings, J.B. (2000), Tutorial Overview of Model Predictive Control, IEEE Control Systems Magazine, 38-52.

Lippke F. (1995), Simulation of the part-load behavior of a 30 MWe SEGS plant, SAND95-1293, Sandia National Laboratories, Albuquerque, NM.

Pilkington (1996), Status Report on Solar Thermal Power Plants, Pilkington Solar International GmbH, Cologne, Germany.

Mancini, T., Sloan, M., Kearney, D. Appel, F., Mahoney, K., Cordeiro, P. (2001), LUZ Heat Collection Element Heat Transfer Analysis Model, Sandia National Laboratory 